\title{
Role of National Culture of Foreign Investors in the Area of Credit Risk Management: Case Study of Polish Banking Industry
}

\author{
Lech Kurklinski \\ Warsaw School of Economics, Warsaw, Poland
}

\begin{abstract}
Among the researches dedicated to the risk management in banks, there are not many analyses made from cultural point of view. The author attempts to assess the attitude to credit risk in the Polish banking system, in terms of cultural factors influencing the approach to this issue. The purpose of this paper is focused on testing the hypothesis that foreign owners of banks (headquarters) transfer elements of their national culture to its subsidiaries operating in Poland. It is done by analysis of statistical correlations between the indexes defining the main characteristics of national cultures and the actual financial performance indicators reached by selected banks in the period from 2004 to 2010 in Poland. The study objectives are the following: Firstly, whether the owners from different countries transfer their cultural attitude to risk to subordinate daughter-banks in Poland. The second question concerns the relevance of uncertainty avoidance and individualism/collectivism concepts of two, to some extent, competing approaches. The findings say that the regularity of the transfer of the cultural attitude to credit risk from the parent banks to their subsidiaries is confirmed by interviews with senior managers, but it is only partially reflected in the statistics. Main outcomes of the study propose that the cultural factors of bank risk management policy shouldn't be ignored and developed in other cross-cultural research areas, e.g. ethnocentrism. Generally, these studies are present lessons for companies, investors, and policymakers, but the usefulness of these implications varies.
\end{abstract}

Keywords: banks, culture, credit risk, uncertainty avoidance, individualism/collectivism

\section{Introduction}

Among the researches dedicated to the risk management in banks, there are not many analysis made from the point of view of the culture which is dominant in particular financial institutions. For this reason, the author attempts to assess the attitude to risk (mainly credit risk) in the Polish banking system, in terms of cultural factors influencing the approach to this issue. The attention is focused on the transfer of elements of national culture related to foreign banks owners to their banks operating in Poland. It is done by analysis of statistical correlations between the indexes defining chosen characteristics of national cultures, and the actual financial performance reached by the selected banks in Poland in the period from 2004 to 2010. The key question is whether the owners from different countries transfer the attitude to risk to the banks subordinated to them in Poland in accordance with their national culture.

Lech Kurklinski, Ph. D., assistant professor, Warsaw School of Economics, Warsaw, Poland.

Correspondence concerning this article should be addressed to Lech Kurklinski, Warsaw School of Economics, Madalińskiego street 6/8, 02-513 Warsaw, Poland. E-mail: lech.kurklinski@data.pl. 


\section{Literature Review}

Interest in the issue of risk in decision-making, especially of an economic and financial nature, has been reported for a long time. One of the first formalized approaches to this issue appeared in the middle of the last century, in the form of the expected utility hypothesis, which is based, inter alia, on the works of Von Neumann and Morgenstern (1945). They pointed to the rationality of behaviour of investors who allocate resources by optimizing their risk preferences (for a given level of risk aversion) associated with perceiving the utility as a linear function of probabilities (Hens \& Wang, 2007).

The expected utility hypothesis was popularised in the traditional approach to finance. However, relatively soon after the works of Von Neumann and Morgenstern, first doubts about their assumptions arose. Allais (1953), the French Nobel Prize winner, drew attention to it, showing an example contradicting the hypothesis, which is known as "Allais paradox". Afterwards, further pieces of evidence pointing to different behaviours were presented by Ellsberg (1961) and Lichtenstein and Slovic (1973).

The need to modify the approach to the role of risk in decision-making and, above all, rationality of choices was also seen by Kahneman and Tversky (1979). According to them, two fundamental conditions had not been taken into consideration: time pressure and information complexity. In order to cope with limited data analysis, heuristics were used. They presented three main types of heuristics, on the basis of which judgements are formed (Kahneman \& Tversky, 1979):

(1) Availability — using information easily available in memory;

(2) Representativeness - taking elements of similarity into account;

(3) Anchoring and adjustment - making use of an initially suggested value (the anchor) to determine the actual value.

Observations of both researchers revealed the duality of the impact of this approach. On one hand, a growing mass of information, its degree of complexity, and the increasing time pressure force people to use simplified models of action, namely heuristics. On the other hand, conventionality and simplifications cause numerous reasoning errors, which are repetitive by nature (Cieślak, 2003).

Research conducted by Kahneman and Tversky led to the descriptive theory of decision making under conditions of uncertainty, called prospect theory. This concept, aiming to show the model describing the actual choices made by individuals, is based on two pillars (Cieślak, 2003).

The value function $v(x)$ is s-shaped and the vehicles for the subjective value (utility) are gains and losses. As regards gains, the value function is concave, but convex for losses as well as milder for gains, and far steeper for losses, which means a stronger response to losses than gains.

The probability weighting function $\pi(p)$ is a non-linear transformation of probabilities which overestimates low probabilities and underestimates medium and high ones.

The shape of a hypothetical value function $v(x)$ - the feeling of pleasure from gain and severity of loss, is shown in Figure 1.

Having taken a closer look at prospect theory, certain questions arise: How does the curve of the value function shape as regards specific communities and how are individual heuristics created under given conditions? It is easy to notice that the procedures (inference) will vary depending on many factors. However, the directory should include a number of the most important cultural factors arising from the national-historical or religious foundations, economic development- the level of well-being etc.. 
The research on reasoning and decision-making under risk has always been carried out according to different cross-sections, including nationality, which can be seen in Figure 2 (Weber \& Hsee, 1998; Hens \& Wang, 2007).

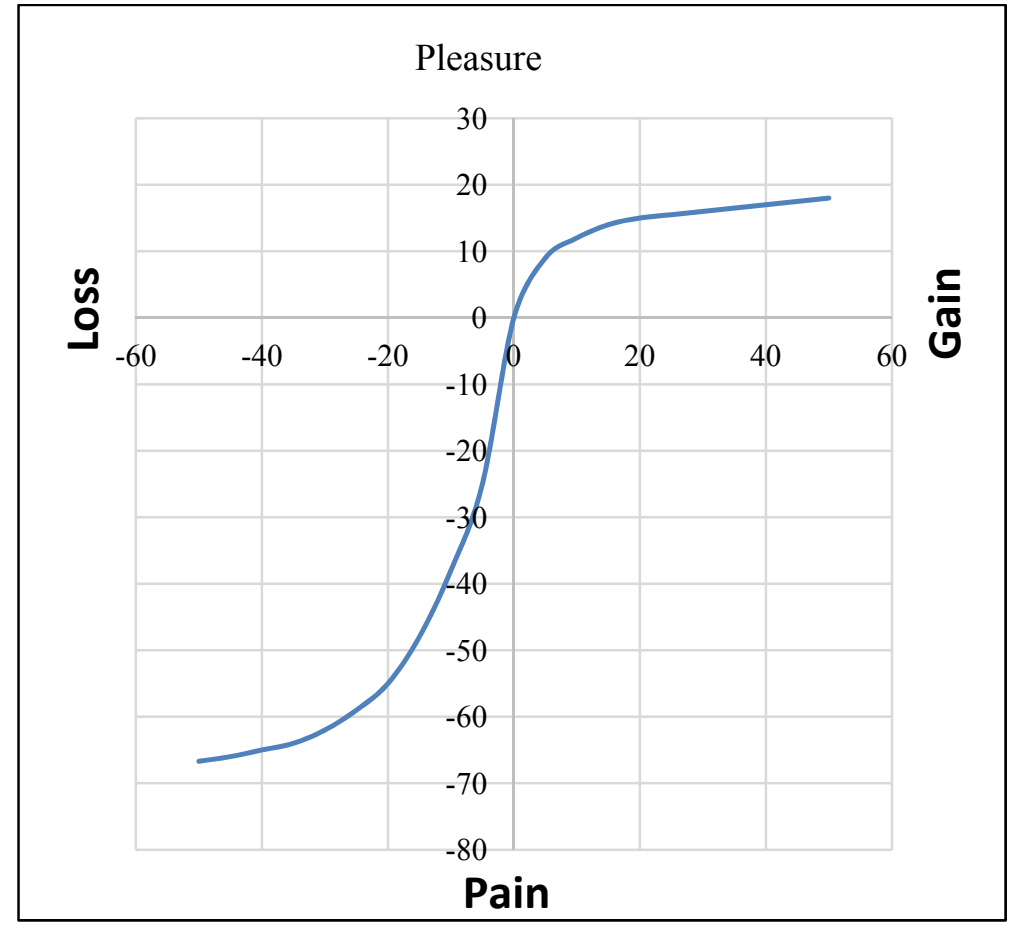

Figure 1. A hypothetical value function $v(x)$ - pleasure and pain. Source: Kahneman and Tversky (1979).

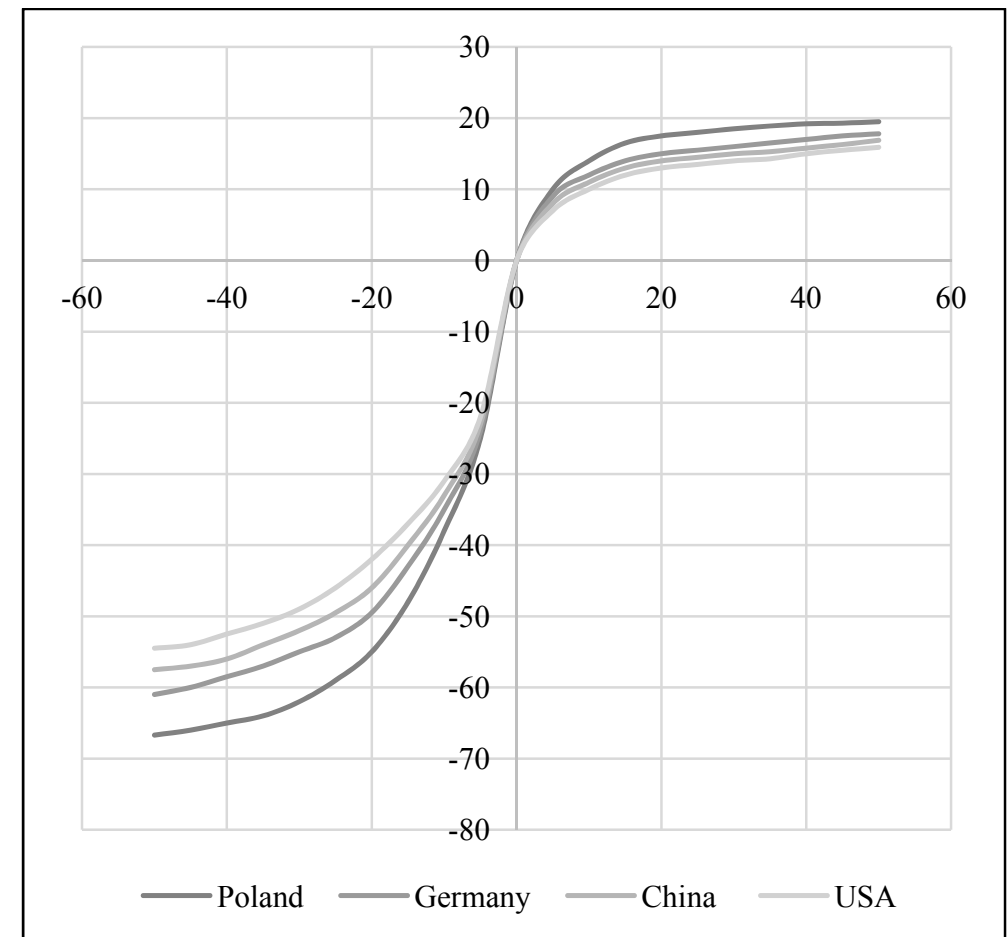

Figure 2. The value function in prospect theory (perceived riskiness)—national cross-section (China, USA, Germany, and Poland). Source: Hens and Wang (2007). 
Against this background, it may be asked: What determines the diversity of risk perception by different societies, and as a consequence of the diversity of decisions, in the case of Poland, why has the curve got such a distinctive shape?

In these circumstances, a slowly increasing scientists" interest in relations between "soft" factors such as culture or religion, and economic development at the macroeconomic or sectoral level (e.g. the banking system) as well as in relation to microeconomic decisions, can be observed. For instance, in 2003, greater attention began to be paid to the role of the dominant religion. In that year, Stulz and Williamson (2003) indicated its more significant impact on the position of financial institutions (mainly banks) than natural openness to foreign trade, the language used or the origin of the legal system in force in a given country. Houston, C. Lin, P. Lin, and Mae (2010), by contrast, emphasised the following relationship: Stronger cultural embeddedness (formal and informal) of lenders (mostly banks) results in their increased tendency to take risks, followed by the probability of a crisis.

In Poland, the religious historical basis had a significant impact on the attitude towards financial institutions and, indirectly, to the issue of risk in the sphere of finance. It was both the huge role of the Catholic Church and the history of the Polish nation-Polish situation until the 18th century, no state in the 19th century, world wars, the period of communism. These experiences affected the restraint of Poles in risk taking, which in recent times can be included to the causes of unconscious prevention of a financial crisis (Poland remained the only country in Europe to avoid recession).

These observations harmonise with the views of Gilles and Hui (2009) adding religion to the key determinants of risk issues and, more broadly, economy. In countries with a higher level of religiousness, especially with the characteristics of a more orthodox, as the Islamic states and to some extent Poland, a lower propensity to take risks is recognised.

Among the analysis dealing with the interdependencies between national culture and economy (including matters of risk), the concepts introduced by Hofstede, House (GLOBE project), Schwartz, Trompenaars, Hampden-Turner are particularly popular (Cozzi, 1998). G. Hofstede and G. J. Hofstede (2005) looked at cultural diversity in terms of four dimensions:

(1) power distance index;

(2) collectivism versus individualism;

(3) masculinity versus femininity;

(4) uncertainty avoidance;

(5) long-term versus short-term orientation;

(6) indulgence versus restraint.

Two dimensions seem to be cardinal for analysing risk attitude: individualism-collectivism and uncertainty avoidance. Both, although slightly differently defined, occurred in the studies by G. Hofstede and G. J. Hofstede (2005) and House, Hanges, Javidan, Dorfman, and Gupta (2004) (GLOBE project).

In countries with a high degree of individualism (IDV-H), it is preferable to achieve success by individuals, which means high competition and rivalry. It naturally leads to increased openness to risk as it does not only mean the hazard, but also an opportunity and the latter aspect come to the fore. It is facilitated by the willingness to take bolder decisions individually rather than with others collectively. Therefore, the collectivist approach of both G. Hofstede and G. J. Hofstede (2005) and the GLOBE project (COL-P: collectivism "P" in practice, COL-V: collectivism "V" in the declared values) should weaken these trends. In order to reduce the 
risk, many banks have procedures that require approval of at least two employees or, going even further, credit committees, i.e. collegial bodies. While collectivist societies have more appreciation for groups, organizations or institutions individualistic societies like benefits of individuals. Adding to this the aggressive incentive systems in banks, then more risky decisions, providing greater opportunities for extra bonuses, are easier to be made with the common approval of the values typical for an individual-oriented society. There is also no strict social control, which could be perceived as an obstacle to a career and achieving success.

In the case of uncertainty avoidance, its connection with the risk appetite or aversion to it should be even more evident. Thus, societies with a low degree of uncertainty avoidance should be more disposed towards taking risks. This is due to, inter alia, greater acceptance of new or unusual circumstances, tolerance, and openness towards other people and innovative projects. Very often, credit applications concern such projects. What is more, as it has been said in the case of individualism, risk/uncertainty may be an opportunity that one should not be afraid to take. On the other hand, strong uncertainty avoidance results from the sense of danger and the need to take preventive actions such as issuing detailed rules and procedures or formalizing interpersonal relations. The future is a threat, and the most important is to provide security. In this sort of situation, instead of counting on substantial benefits, there is a tendency not to take risky decisions accompanied by unwillingness to innovate and a low level of acceptance of different behaviours and beliefs. Under these conditions, the borrowers encounter a lot of difficulties to get their ventures financed. This is G. Hofstede and G. J. Hofstede's approach (UAI-H). However, in the GLOBE project (UAI-P and UAI-V), fear is not emphasised, but the tendency to avoid uncertainty means adherence to procedures and policies-life in an orderly world. Therefore, a generally inverse correlation between this index and the G. Hofstede and G. J. Hofstede's study and the GLOBE project is not surprising (Boski, 2009).

The argumentation above should indicate a strong relationship among all presented conceptualizations of national cultures based upon the approach to risk. In the case of IDV-H, it is a positive correlation, in other words, the greater the level of individualism, the stronger the tendency to accept risk. As to the UAI (H, P, V), the indexes should show a negative correlation. A society with a high degree of uncertainty avoidance tendency is characterised by a strong risk aversion. These observations were confirmed by an empirical research. In cooperation with Chinese scientists, Griffin proved the existence of correlations between national culture (seen primarily by means of IDV and UAI-H-H indexes) and the tendency of non-financial companies to accept the risk (Griffin, Li, Yue, \& Zhao, 2009). A confirmation was also obtained by research in other sections such as, among others, marketing or, more generally, management. However, in this paper, the most essential point is to demonstrate the connection of these relations with banking business, dealing with a higher level of uncertainty results from a specific diversity and complexity of particular trades. Banks financing the most diverse companies must assess the risks associated with their activity without being specialists in these fields. The research conducted by Kanagaretnam, Lim, and Lobo (2011) on banks from 45 countries (already after the recent financial crisis) also showed the relationship between national culture and the willingness to take risks. In addition, it has shown that the level of risk exposure goes hand in hand with a threat to the safety of banks expressed through their financial problems observed during the global crisis which started in 2007 (Kanagaretnam et al., 2011).

\section{Appetite for Risk in Selected Banks in Poland and National Culture}

Assuming that there is a relationship between national culture (in terms of the level of 
individualism/collectivism and uncertainty avoidance) and the propensity to take risks in the banking industry in international terms, it might be asked whether a similar relationship exists with relation to particular banks, distinguished by the criterion of the country of origin of their owners (capital). Looking at the results of the entire financial system in Poland compared to other European countries, especially in the face of the global crisis, they are really good and show a low level of risk in banks in Poland. Comparing them with a particularly high uncertainty avoidance index, the regularity mentioned in the introduction would be confirmed. However, examining this relationship on the micro level is not so clear-cut. It seems that the answer to the question may be obtained by examining (using Pearson's index) the correlation of particular results of banks, especially those reflecting the risk appetite with the indicators of individualism (IDV-G) - collectivism (the GLOBE project in practical terms COL-P and declarative values of COL-V), and similarly, uncertainty avoidance, the national cultures of dominant investors. The key to the selection of banks for the evaluation was the following criteria: the scale of activity - the biggest banks in Poland, the universal nature, the availability of data for the period from 2004 to 2010 and the lack of mergers and acquisitions in the period considered. In these circumstances, the analysis included the following banks: PKO Polish Bank SA, Bank Pekao SA, BRE Bank SA, ING Bank Slaski SA, BZ WBK, Bank Handlowy in Warsaw (Citi), Bank Millennium SA, Kredyt Bank SA, Nordea Bank Poland SA, and Raiffeisen Bank Poland SA (see Table 1). In terms of the country of origin of the main shareholder, the above banks will be confronted with the national cultures in Poland, Italy, Germany, Netherlands, Ireland, USA, Portugal, Belgium, Sweden, ${ }^{1}$ and Austria, respectively.

Table 1

Selected Banks in Poland and Cultural Dimensions of Countries of Origin of Major Shareholders

\begin{tabular}{llllllll}
\hline Bank & Country & IDV-H & COL-P & COL-V & UAI-H & UAI -P & UAI-V \\
\hline Citi & USA & 91 & 4.21 & 4.2 & 46 & 4.15 & 3.99 \\
ING & Netherlands & 80 & 4.62 & 4.76 & 53 & 4.81 & 3.34 \\
PEKAO & Italy & 76 & 3.75 & 5.2 & 75 & 3.85 & 4.52 \\
Nordea & Sweden & 71 & 5.26 & 3.91 & 29 & 5.36 & 3.45 \\
BZ WBK & Irland & 70 & 4.57 & 4.55 & 35 & 4.25 & 3.94 \\
BRE & Germany & 67 & 3.97 & 5.07 & 65 & 5.35 & 3.38 \\
PKO BP & Poland & 60 & 4.51 & 4.24 & 93 & 3.71 & 4.75 \\
Raiffeisen & Austria & 55 & 4.89 & 5.32 & 70 & 5.1 & 3.65 \\
Millennium & Portugal & 27 & 4.02 & 5.4 & 104 & 3.96 & 4.5 \\
\hline
\end{tabular}

Notes. IDV-H: individualism index; COL-P: ollectivism index in practice (GLOBE; COL-V: the collectivism index-declared values (GLOBE); UAI-H: uncertainty avoidance index; UAI-P: uncertainty avoidance index in practice (GLOBE); UAI-V: uncertainty avoidance index — declared values (GLOBE). Source: G. Hofstede and G. J. Hofstede (2005).

When it comes to risk perception by banks, the main concern of the author is credit risk, as the approach to it can be relatively easily interpreted. Thus, two aspects were taken into account: the dynamics of increase/decrease of the volume of credits and loans granted to customers and the quality of the credit portfolio. There is no doubt that credits usually belong to the assets of the greatest risk, hence the selection of their annual growth, as when granted quickly and on large scale they carry a great deal of risk. However, it is crucial to remember that a risk is not only a threat, but also an opportunity. Intensive development of lending comes primarily from a bank's revenue growth, as loans mean that high interest assets appear on the balance sheet and

\footnotetext{
${ }^{1}$ The Nordea Group has a wider Scandinavian nature, however, the cultures of the other countries, that is Denmark and Finland, are similar to Swedish.
} 
provide service charges. Theoretically, one can imagine a significant increase in lending and a very good quality of the portfolio, which would indicate both a great appetite for risk and good risk management. In practice, generally strong credit growth leads to numerous difficulties in paying off loans, but Polish experiences show that such "theoretical" cases might happen. The following Table 2 shows the growth rate of credit volumes and loans since 2004.

Table 2

Dynamics of Lending to Customers (Percentile Year-on-year Growth From 2004/05 to 2009/10)

\begin{tabular}{lccccccc}
\hline Bank & 2005 & 2006 & 2007 & 2008 & 2009 & 2010 & Y/Y average \\
\hline Citi Handlowy & 91 & 106 & 112 & 110 & 87 & 99 & 101 \\
BZ WBK & 110 & 124 & 136 & 147 & 93 & 98 & 118 \\
Kredyt Bank & 85 & 119 & 144 & 161 & 96 & 105 & 118 \\
Raiffeisen & 129 & 132 & 126 & 132 & 90 & 103 & 119 \\
Banking sector & 113.5 & 124.9 & 132.5 & 142.2 & 105.5 & 108.9 & 121.2 \\
PKO BP & 118 & 126 & 130 & 132 & 113 & 113 & 122 \\
ING & 95 & 131 & 126 & 157 & 119 & 113 & 124 \\
PEKAO SA & 108 & 113 & 210 & 119 & 97 & 102 & 125 \\
BRE & 107 & 150 & 146 & 155 & 101 & 113 & 129 \\
Millennium & 126 & 156 & 147 & 153 & 99 & 110 & 132 \\
Nordea & 110 & 133 & 162 & 158 & 124 & 122 & 135 \\
\hline
\end{tabular}

Source: Own study based on the ranking of the 50 largest banks prepared annually by a monthly financial magazine "BANK" and reports of the Financial Supervision Authority.

The bank with the most dynamic growth in loans in the years from 2004 to 2010 was Nordea Bank, in comparison to the end of 2004 when the bank was at the bottom of the list with the lowest volume of loans, nearly three times lower than Citi Handlowy Bank. Therefore, one could say that at low absolute values, it is much easier to achieve a high rate of growth. However, in 2010 Nordea's level of lending was nearly twice as high as Citi Handlowy's. Thus, regardless of the relatively low initial states, their growth in the period of six years was impressive; on the other hand, the data on non-performing loans shows that the bank achieved the best quality of the portfolio of the surveyed institutions. Citi Handlowy Bank is at the opposite pole with its stagnating results, interim fluctuations, and the quality of the loan portfolio was the lowest. In terms of IDV-H index and COL-P, COL-V (GLOBE), the comparison of banks is shown in Table 3.

Table 3

IDV-H and COL-P, COL-V Indexes in Relation to the Dynamics of Lending to Customers From 2004 to 2010

\begin{tabular}{llllll}
\hline Bank & Country & IDV-H & COLL-P & COLL-V & Y/Y average (\%) \\
\hline Citi & USA & 91 & 4.21 & 4.2 & 101 \\
ING & Netherlands & 80 & 4.62 & 4.76 & 124 \\
PEKAO & Italy & 76 & 3.75 & 5.2 & 125 \\
Nordea & Sweden & 71 & 5.26 & 3.91 & 135 \\
BZ WBK & Ireland & 70 & 4.57 & 4.55 & 118 \\
BRE & Germany & 67 & 3.97 & 5.07 & 129 \\
PKO BP & Poland & 60 & 4.51 & 4.24 & 122 \\
Raiffeisen & Austria & 55 & 4.89 & 5.32 & 119 \\
Millennium & Portugal & 27 & 4.02 & 5.4 & 132 \\
\hline
\end{tabular}

Source: Own study. 
The table above shows a surprisingly low position of Millennium Bank, while the Portuguese IDV-H index is the lowest and COL-V the highest, and the increase in one of the largest loans. This particular case is quite contrary to the thesis that high levels of individualism promote appetite for risk in these conditions. The results of the dynamics of credit growth study year-on-year with IDV-H index (Pearson correlation index -0.53) and COL-P, COL-V ( +0.12 and +0.23 respectively) for the entire sample, present a correlation almost contradictory to what had been assumed. Independently of the evaluation of the strength of these relationships, it can be concluded that there is no positive relationship between the degree of focus on individualism (at least when defined by the indexes) which is characteristic for the origin country of the main shareholder of the bank, with the results reflected in risk appetite - the desire to build the largest loan portfolio. Thus, how does the situation develop when it comes for UAI-index of uncertainty avoidance (Table 4)?

Table 4

UAI-H and UAI-P, UAI-V Indexes in Relation to the Average (Year on Year) Dynamics of Lending to Customers From 2004 to 2010

\begin{tabular}{llclll}
\hline Bank & Country & UAI-H & UAI-P & UAI-V & Y/Y average(\%) \\
\hline Nordea & Sweden & 29 & 5.36 & 3.45 & 135 \\
BZ WBK & Ireland & 35 & 4.25 & 3.94 & 118 \\
Citi & USA & 46 & 4.15 & 3.99 & 101 \\
ING & Netherlands & 53 & 4.81 & 3.34 & 124 \\
BRE & Germany & 65 & 5.35 & 3.38 & 129 \\
Raiffeisen & Austria & 70 & 5.1 & 3.65 & 119 \\
PEKAO & Italy & 75 & 3.85 & 4.52 & 125 \\
PKO BP & Poland & 93 & 3.71 & 4.75 & 122 \\
Millennium & Portugal & 104 & 3.96 & 4.5 & 132 \\
\hline
\end{tabular}

Source: Own study.

In this case, the leader of this sheet-Nordea, is in fact accompanied by the lowest level of uncertainty avoidance, but the completely different results of Millennium and Citi Handlowy or BZ WBK would indicate just the opposite. When it comes to UAI-H and UAI-P indexes, a very loose positive relationship with credit dynamics can be seen (correlation +0.22 and +0.32 respectively), and only UAI-V index has a negative minimal dimension $(-0.10)$, which generally contradicts the thesis in the introduction that the growth of the uncertainty avoidance rate is accompanied by limitation of risk-taking. For a more complete verification of the thesis another cross-sectional survey on the attitudes of banks to risk-taking was suggested - shaping of non-performing loans share (see Table 5 and 6).

In this section, as it has been indicated, Nordea Bank Poland stands out.

Nordea has almost three times better quality of credit receivables than Citi at a much smaller difference in UAI-H index rates ( 71 and 91 points), and in Portugal (27 points) with the loan portfolio worse by $45 \%$. However, by looking at the analysis of all the surveyed banks and examining their correlation, a big similarity can be noticed between G. Hofstede's indexes and the GLOBE project (especially from the practical point of view). Pearson's coefficient for the IDV-H is +0.40 and for the COL-P -0.56 . The first case confirms the thesis that the growth of individualism is accompanied by increase in bad loan portfolio (higher risk), and for the research on the GLOBE project the increase of collectivism (decrease of individualism) means improving the quality of loans. 
Table 5

Share of Non-performing Loans in Total Loans in \%

\begin{tabular}{lrrrrrrrr}
\hline Bank & 2004 & 2005 & 2006 & 2007 & 2008 & 2009 & 2010 & Average \\
\hline Nordea & 16.0 & 11.5 & 4.9 & 1.7 & 1.1 & 0.8 & 1.0 & 5.3 \\
Raiffeisen & 9.6 & 7.3 & 2.5 & 2.7 & 3.8 & 5.9 & 5.3 & 5.3 \\
BZ WBK & 8.5 & 7.0 & 4.9 & 2.7 & 2.7 & 5.3 & 6.5 & 5.4 \\
ING & 11.5 & 7.9 & 5.1 & 3.0 & 2.1 & 4.4 & 4.9 & 5.6 \\
PKO BP & 8.9 & 6.9 & 4.4 & 3.9 & 3.8 & 7.0 & 7.4 & 6.0 \\
BRE & 12.4 & 8.5 & 5.5 & 3.6 & 2.8 & 5.9 & 5.3 & 6.3 \\
Millennium & 20.0 & 10.0 & 5.7 & 3.4 & 3.4 & 5.9 & 5.8 & 7.7 \\
Banking sector & 14.9 & 11 & 7.4 & 5.1 & 4.5 & 7.5 & 7.8 & 8.3 \\
PEKAO & 19.9 & 16.2 & 11.8 & 7.8 & 5.5 & 6.8 & 7.0 & 10.7 \\
Citi Handlowy & 19.0 & 19.0 & 16.0 & 11.8 & 12.3 & 11.9 & 11.8 & 14.5 \\
Kredyt Bank & 30.2 & 28.7 & 13.5 & 6.6 & 4.9 & 8.7 & 9.7 & 14.6
\end{tabular}

Source: Own study based on annual reports of banks, stock exchange reports, documents posted on the websites of the banks, and reports of the Financial Supervision Authority.

Table 6

$I D V-H$ and COL-P, COL-V Indexes in Relation to the Average Share of Non-performing Loans (NPL) in Total Loans in the Period From 2004 to 2010 in \%

\begin{tabular}{llcccc}
\hline Bank & Country & NPL & COLL-P & COLL-V & IDV-H \\
\hline Nordea & Sweden & 5.3 & 5.26 & 3.91 & 71 \\
Raiffeisen & Austria & 5.3 & 4.89 & 5.32 & 55 \\
BZ WBK & Ireland & 5.4 & 4.57 & 4.55 & 70 \\
ING & Netherlands & 5.6 & 4.62 & 4.76 & 80 \\
PKO BP & Poland & 6 & 4.51 & 4.24 & 60 \\
BRE & Germany & 6.3 & 3.97 & 5.07 & 67 \\
Millennium & Portugal & 7.7 & 4.02 & 5.4 & 27 \\
PEKAO & Italy & 10.7 & 3.75 & 5.2 & 76 \\
Citi Handlowy & USA & 14.5 & 4.21 & 4.2 & 91 \\
\hline
\end{tabular}

Source: Own study.

As regards the UAI index, the situation is completely different. The least threatened by bad loans is Nordea, for which the level of uncertainty avoidance should achieve the highest ceiling. However, according to Hofstede's studies, the main shareholder has the smallest fear of uncertainty and, in this respect, is among the European leaders (see Table 7).

The distribution of the results of the average share of the non-performing loans receivables in relation to UAI-H index has a neutral value (coefficient of correlation +0.03 ), but for UAI-P, it is definitely clearer and negative (-0.47) and for UAI-V (+0.34). The UAI-P results moderately confirm the idea that a higher propensity to avoid uncertainty should favour smaller risk, but the UAI-V results do not. Surprisingly, there is a significant discrepancy between the practice of avoiding uncertainty and the declared values.

In summary, the results of the correlation between the average of credit volume growth to customers and the average share of non-performing loans in the years from 2004 to 2010, for particular banks, in relation to IDV-H, the COL-P, COL-V, and uncertainty avoidance UAI $(\mathrm{H}, \mathrm{P}, \mathrm{V})$ of the country of origin of the main 
shareholder of these institutions, at least did not confirm the thesis clearly put forward in the introduction (see Table 8).

Table 7

UAI-H, UAI-P, and UAI-V Indexes in Relation to the Average Share of Non-performing Loans (NPL) to Total Loans in the Period From 2004 to 2010 in \%

\begin{tabular}{llcllc}
\hline Bank & Country & NLP & UAI -P & UAI-V & UAI-H \\
\hline Nordea & Sweden & 5.3 & 5.36 & 3.45 & 29 \\
Raiffeisen & Austria & 5.3 & 5.1 & 3.65 & 70 \\
BZ WBK & Ireland & 5.4 & 4.25 & 3.94 & 35 \\
ING & Netherlands & 5.6 & 4.81 & 3.34 & 53 \\
PKO BP & Poland & 6 & 3.71 & 4.75 & 93 \\
BRE & Germany & 6.3 & 5.35 & 3.38 & 65 \\
Millennium & Portugal & 7.7 & 3.96 & 4.5 & 104 \\
PEKAO & Italy & 10.7 & 3.85 & 4.52 & 75 \\
Citi Handlowy & USA & 14.5 & 4.15 & 3.99 & 46 \\
\hline
\end{tabular}

Source: Own study.

Table 8

Coefficients of Non-performing Loans Correlations and Credit Dynamics in Regard to the Indicators of Individualism/Collectivism and Uncertainty Avoidance

\begin{tabular}{lcc}
\hline & NPL & Loan dynamics \\
\hline IDV-H & +0.40 & -0.53 \\
COL-P & -0.56 & +0.12 \\
COL-V & -0.07 & +0.23 \\
UAI-H & +0.03 & +0.22 \\
UAI-P & -0.47 & +0.32 \\
UAI-V & 0.34 & -0.10 \\
\hline
\end{tabular}

Source: Own study.

It reads as follows: Major shareholders from different countries introduce the attitude towards risk typical for their culture into banks in Poland, expressed in the indexes of degree of individualism/collectivism of a particular society and uncertainty avoidance, developed by G. Hofstede and R. J. House team (the GLOBE project). Only the correlation between the size of non-performing loans and IDV-H coefficients of individualism and practical collectivism of GLOBE (COL-P) may indicate a relationship between the measured areas. Nevertheless, nearly all the other values are low, which opens the door for further research of the relationships of national and corporate cultures in relation to the ways of managing financial institutions in Poland and their performance.

Probably, the return to the assessment of the impact of various aspects of the organizational/national culture of banking groups in the management, operations and results of their subsidiaries should be required. A study conducted by Italian researchers (Carretta, Farina, Fiordelisi, \& Schwizer, 2008) for major banks in France, Italy, Germany, and the UK, showed the existence, albeit limited, of these relations. In the short term, they found no correlation between bank performances and the organizational culture, but pointed to its 
importance in achieving strategic objectives. The old banking cultures, bureaucratic and based on mechanistic models, become development barriers and give way to cultures focused on people and cooperation. In addition, as shareholders see it, results-oriented attitude seems destructive to the value of the banks, as it usually creates more pressure on short-term results achieved through an increase in risk.

\section{Conclusions}

Partially negative results of the research may stimulate a discussion on a broader interpretation. Is the management of banks in Poland really characterised by a degree of autonomy in relation to the influence of national cultures of their main shareholders? On the basis of the opinion of top bank managers, the image of banking in Poland appears to be quite different. Thus, have the values of risk been selected properly? Aren't they too small? Should the main attention focus on the other aspects of culture, such as the level of ethnocentrism of foreign investors? Interviews conducted by the author with the managements of banks indicate the existence of a strong relationship, e.g.: a huge level of institutional ethnocentrism in Citibank and disastrous results and a high level of Scandinavian cultural tolerance-a great achievement of Nordea bank. However, it would be a different study that might be taken in the future.

Generally, it can be said that the issue of the influence of both national and organizational cultures on financial institutions has so far been underestimated by researchers. Perhaps this was due to the dominance of the expected utility hypothesis in the world of finance (with focus on the rationality of decisions), but with its "undermining" (or according to other opinions "essential complement"), the importance of cultural factors should be reflected more broadly in the new research.

\section{References}

Allais, M. (1953). Le Comportement de l'Homme Rationnel Devant Le Risque: Critique des Postulats et Axiomes de L'Ecole Americaine (The behavior of rational man in front of the critical risk assumptions and axioms of the American school). Econometrica, 21(4), 503-546.

Boski, P. (2009). Kulturowe ramy zachowań społecznych. Podręcznik psychologii międzykulturowej (Cultural framework of social behaviour). Warszawa: PWN.

Carretta A., Farina, V., Fiordelisi, F., \& Schwizer, P. (2008). Corporate culture and shareholder value in banking industry (MPRA Paper No. 8304, Munich, April).

Cieślak, A. (2003). Behawioralna ekonomia finansowa. Modyfikacja paradygmatów funkcjonujących w nowoczesnej teorii finansów (Behavioural financial economics. Modification of operating paradigms in modern finance theory). Warsaw: Materiały i Studia.

Cozzi, G. (1998). Culture as a bubble. Journal of Political Economy, 106(2), 376-394.

Ellsberg, D. (1961). Risk, ambiguity, and the savage axioms. Quarterly Journal of Economics, 75, 643-669.

Gilles, H., \& Hui, K. (2009). Does religion matter in corporate decision making in America? Journal of Financial Economics, 93, 455-473.

Griffin, D., Li, K., Yue, H., \& Zhao, L. (2009). Cultural values and corporate risk-taking (Working Paper, University of British Columbia and Peking University).

Hens, T., \& Wang, M. (2007). Does finance have a cultural dimension (National Centre of Competence in Research Financial Valuation and Risk Management, Working Paper No. 377, April 24).

Hofstede, G., \& Hofstede, G. J. (2005). Cultures and organizations: Software of the mind (2nd ed.). New York: McGraw-Hill.

House, R. J., Hanges, P. J., Javidan, M., Dorfman, P. W., \& Gupta, V. (2004). Culture, leadership, and organizations: The globe study of 62 societies. Thousand Oaks: Sage Publications.

Houston, J., Lin, C., Lin, P., \& Mae, Y. (2010). Creditor rights, information sharing, and bank risk taking. Journal of Financial Economics, 96(3), 485-512.

Kahneman, D., \& Tversky, A. (1979). Prospect theory: An analysis of decisions under risk. Econometrica, 47(2), $263-291$. 
Kanagaretnam, K., Lim, C., \& Lobo, G. (2011). Effects of national culture on bank risk taking. Journal of International Business Studies, 42, 853-874.

Lichtenstein, S., \& Slovic, P. (1973). Response-induced reversals of preferences in gambling: An extended replication in Las Vegas. Journal of Experimental Psychology, 101(1), 16-20.

Stulz, R., \& Williamson, R. (2003). Culture, openness, and finance. Journal of Financial Economics, 70, 313-349.

Von Neumann, J., \& Morgenstern, O. (1945). Theory of games and economic behavior. Bulletin of the American Mathematical Society, 51(7), 498-504.

Weber, E., \& Hsee, C. (1998). Cross-cultural differences in risk perception, but cross-cultural similarities in attitudes towards perceived risk. Management Science, 44(9), 1205-1217. 